\title{
2013 ADSA-ASAS Sectional Award
}

\section{Recipient of the Northeast ADSA-ASAS Young Scientist-Research}

Kristen E. Govoni earned her BS degree in animal science from the University of Connecticut in 1998 and then, under the mentorship of S. A. Zinn, earned her MS (2002) and PhD (2003) (2) degrees. Her dissertation research focused on growth physiology, endocrinology and the response of the somatotropic axis and insulinlike growth factor binding proteins to exogenous growth hormone in growing animals using beef, dairy and swine models. She also had a minor concentration in statistical analysis and the analysis of temporal and spatial correlations in the MIXED model procedures. After completing her graduate education, Govoni worked with S. Mohan at the Musculoskeletal Disease Center in the Jerry L. Pettis VA Medical Center in Loma Linda, California. During her postdoctoral training, Govoni's research focused on the role of growth hormone and insulin-like growth factor-I in the regulation of bone metabolism. During her five years in California, her research focused on four specific areas: (1) identification of target genes involved in regulating growth hormone action in bone; (2) determination of genetic loci that regulate IGF-I action during pre-pubertal growth; (3) evaluation of the role of IGF-I in peak bone mineral density; and (4) endosteal bone volume regulation.

Upon completing her postdoctoral training in 2008, Govoni joined the faculty in the Department of Animal
Science at University of Connecticut as an assistant professor. She currently holds this position with an active research program and teaching responsibilities. Govoni's current research focuses on understanding growth and development at the cellular level to identify methods to improve animal health and efficiency of production. Currently, her laboratory has two major focuses. The first is to determine the effects of poor maternal nutrition on pre- and postnatal development using a sheep model. In particular, she and her students are working to determine the effects of under- and overfeeding during gestation on muscle, bone and adipose tissue as well as the potential programming effects of maternal diet on mesenchymal stem cells in the offspring. The second focus is to determine molecular mechanisms involved in the attachment and invasion of Staphylococcus aureus in the bovine mammary gland using whole transcriptome analysis. In addition, they are investigating the effectiveness of plant-derived antimicrobials to prevent and treat mastitis in cattle. Govoni has supervised 4 MS students and currently has $1 \mathrm{MS}$ and $2 \mathrm{PhD}$ candidates in the laboratory. Dr. Govoni teaches three courses in the department. She was the instructor for the undergraduate Principles of Animal Nutrition course for 4 years, the undergraduate Animal Science Seminar course for 5 years, and is the new instructor for Growth Biology and Metabolism course. In addition to her teaching efforts, Govoni is a strong proponent of undergraduate research. She has mentored over 20 undergraduates, including 3 honors projects, in research during her five years at UConn. Kristen Govoni currently lives in Lebanon, Connecticut, with her husband and two young boys.

In her short career, Govoni has had extraordinary success and is extremely deserving of the 2013 Northeast ADSA-ASAS Young Scientist-Research Award. 